\title{
O MECANISMO EXPERIMENTAL DE ACREDITAÇÃO DO MERCOSUL (MEXA): A CONSTRUÇÃO dE UM PROCESSO REGIONAL DE CERTIFICAÇÃO DE QUALDADE DE CURSOS DE GRADUAÇÃo
}

\author{
THE EXPERIMENTAL ACCREDITATION MECHANISM OF MERCOSUR: \\ THE CONSTRUCTION OF A REGIONAL QUALITY ASSURANCE PROCESS \\ FOR UNDERGRADUATE COURSES
}
EL MECANISMO EXPERIMENTAL DE ACREDITACIÓN DEL MERCOSUR:
LA CONSTRUCCIÓN DE UN PROCESO REGIONAL DE CERTIFICACIÓN DE LA
CALIDAD DE CARRERAS DE GRADO

\section{Gabriella de Camargo Hizume ${ }^{1}$ Gladys Beatriz Barreyro ${ }^{2}$}

\begin{abstract}
RESUMO: Este estudo objetiva apresentar e analisar a elaboração e o desenvolvimento do Mecanismo Experimental (Mexa) que deu origem ao processo regional de acreditação de cursos universitários do Mercado Comum do Sul (Mercosul). Para tanto, abordaram-se a concepção de seu desenho, sua aplicação, seus impactos e suas contribuições para o estabelecimento do Sistema de Acreditação Regional de Cursos Universitários. Metodologicamente, a pesquisa se baseou em análise documental e em entrevistas realizadas com sujeitos que participaram da elaboração e/ou aplicação do Mecanismo, enfocando-se a atuação dos Estados-membro originários do bloco. Aferiu-se que se por um lado é possível considerar que o Mexa favoreceu a cultura da avaliação e da acreditação do ensino superior na região, trazendo como logro a construção conjunta de todo o processo por seus participantes, por outro, as limitações de seu caráter experimental eivaram de vícios o processo regional, obstaculizando sua aplicação em larga escala.
\end{abstract}

PALAVRAS-CHAVE: Mercosul. Mexa. Certificação de Qualidade. Educação Superior.

ABSTRACT: This study goals to present and analyze the elaboration and development of the Experimental Mechanism (Mexa) that gave rise to the regional accreditation process of undergraduate courses of the Common Market of the South (Mercosur). For that, the conception of its design, its application, its impacts and its contributions to the establishment of the Regional Accreditation System of Undergraduate Courses were approached. Methodologically, the research was based on documentary analysis and interviews with people who participated in the elaboration and / or application of the Mechanism, focusing on the actions of the Member States that founded the bloc. It was verified that if on the one hand it is possible to consider that the Mexa favored the culture of the evaluation and the accreditation of the higher education in the region, bringing as achievement the joint construction of the whole process by its participants, on the other, the limitations of its experimental character created some problems for the regional process, hindering its application on a large scale.

KEYWORDS: Mercosur. Mexa. Quality assurance. Higher education.

RESUMEN: Este estudio tiene como objetivo presentar y analizar la elaboración y el desarrollo del Mecanismo Experimental (Mexa) que originó el proceso regional de acreditación de carreras de grado del Mercado Común del Sur (Mercosur). Fueron considerados la concepción, su diseño, su aplicación, sus impactos y las

\footnotetext{
${ }^{1}$ Universidade Estadual do Oeste do Paraná. E-mail: ghizume@ yahoo.com.br - ORCID: http://orcid.org/00000001-8321-356X

${ }^{2}$ Universidade de São Paulo. E-mail: gladysb@usp.br - ORCID: http://orcid.org/0000-0002-2714-5811 Submetido em: 28-11-2016 - Aceito em: 05-12-2016 - Publicado em: 02-02-2017

\begin{tabular}{l|l|l|l|l|l|l} 
(C) Rev. Inter. Educ. Sup. & Campinas, SP & v.3 & n.1 & p.46-65 & jan./abr. 2017 & ISSN 2446-9424
\end{tabular}
}


contribuiciones para el establecimiento del Sistema de Acreditación Regional de Carreras Universitarias. Metodologicamente, la pesquisa se basó en: análisis documental y en entrevistas realizadas con participantes de la elaboración y/o aplicación del Mecanismo, enfocándose las acciones de los Estados miembros originarios del bloque. Por fin, se concluye que, si por un lado es posible considerar que el Mexa favoreció la cultura de evaluación y de acreditación de la educación superior en la región, teniendo como logro la participación de los Estados en en su construcción; por otro lado, las limitaciones de su carácter experimental le generaron vicios al processo regional que dificultan su aplicación en gran escala.

PALABRAS CLAVE: Mercosur. Mexa. Certificación de Calidad. Educación Superior.

\section{INTRODUÇÃO}

No Mercado Comum do Sul (Mercosul), a circulação de profissionais diplomados foi percebida como essencial para se atingir os objetivos do bloco econômico regional desde sua constituição, em 1991 pelo Tratado de Assunção, com o trânsito de mão de obra qualificada e a emergência de um mercado de trabalho transnacional. Para verificar as reais possibilidades de tal intento, em 1996, foram iniciados os trabalhos sobre o reconhecimento de títulos de graduação intrabloco que resultaram no entendimento de que o tema envolvia, primeiramente, a equivalência dos cursos de graduação e a certificação de sua qualidade. Assim, em 1998, foi aprovado pela Reunião de Ministros da Educação o Memorando de Entendimento sobre a Implementação de um Mecanismo Experimental de Acreditação de Cursos para o Reconhecimento de Títulos de Graduação Universitária nos Países do Mercosul, Bolívia e Chile (Mexa) em que foram definidas as diretrizes de um processo de acreditação comum para os Estados participantes.

O Mexa foi inserido no Plano Operacional do Setor Educacional do Mercosul como política pública regional de certificação de qualidade de cursos de graduação e excelência acadêmica e teve a versão final de seus princípios e normas aprovada em 2002 na XXII Reunião dos Ministros de Educação.

Aplicado entre 2002 e 2006, o Mexa resultou na acreditação de 62 cursos e foi tomado como modelo para a instituição do Sistema de Acreditação Regional de Cursos Universitários do Mercosul (Sistema Arcu-Sul), de caráter permanente, hoje em vigor.

Assim, objetiva-se com este texto resgatar o processo de construção do Mexa e seus meandros para, então, adentrar na análise de seus desdobramentos e contribuições para a cultura de avaliação da educação superior na região, com foco nos quatro Estados-membro originários do bloco (Argentina, Brasil, Paraguai e Uruguai). Para a elaboração deste estudo, que é parte de pesquisas mais amplas sobre o Sistema Arcu-Sur, foram utilizadas técnicas de pesquisa documental e bibliográfica com entrevistas realizadas com sujeitos que participaram da elaboração e/ou aplicação do Mexa. Nota-se que uma das finalidades deste texto consiste em contribuir para o registro de informações sobre do Mecanismo Experimental, tendo em vista que vários dos dados coletados, mesmo em fontes oficiais, apresentam divergência.

\begin{tabular}{l|l} 
n.1 & p.46-65
\end{tabular}




\section{BREVES CONSIDERAÇõeS SOBRE O SETOR EDUCACIONAL DO MERCOSUL}

Para se apreender o contexto institucional em que se desenvolve o Mexa, primeiramente, faz-se necessário tecer algumas considerações sobre a organização do Setor Educacional do Mercosul (SEM).

Criado no mesmo ano que o bloco por iniciativa dos Ministros de Educação, o SEM foi instituído como fórum específico para tratar da Educação em todos os seus níveis e em suas dimensões regionais; nele, desembocam temáticas adjacentes que exigem estratégias particulares e pontuais como a circulação de mão-de-obra qualificada, um dos pilares dos processos de integração, que envolve a aferição da correspondência e comparabilidade da formação do nível superior, reconhecimento de títulos universitários, procedimentos de avaliação e mecanismos de acreditação de cursos de graduação, mobilidade estudantil, docente e técnico-científica, seguindo os movimentos de internacionalização e regionalização da Educação Superior.

Como observa Hermo (2011), diferentemente de outros blocos econômicos regionais, no Mercosul a questão educacional se desenvolveu simultaneamente às searas econômica e comercial, o que explicaria ter-se alcançado patamares de discussão tão avançados na área educacional comparativamente.

O SEM tem como órgão máximo a Reunião de Ministros de Educação (RME), que ao longo dos anos criou instâncias para dar suporte à sua expansão, podendo ser visualizado seu organograma a seguir.

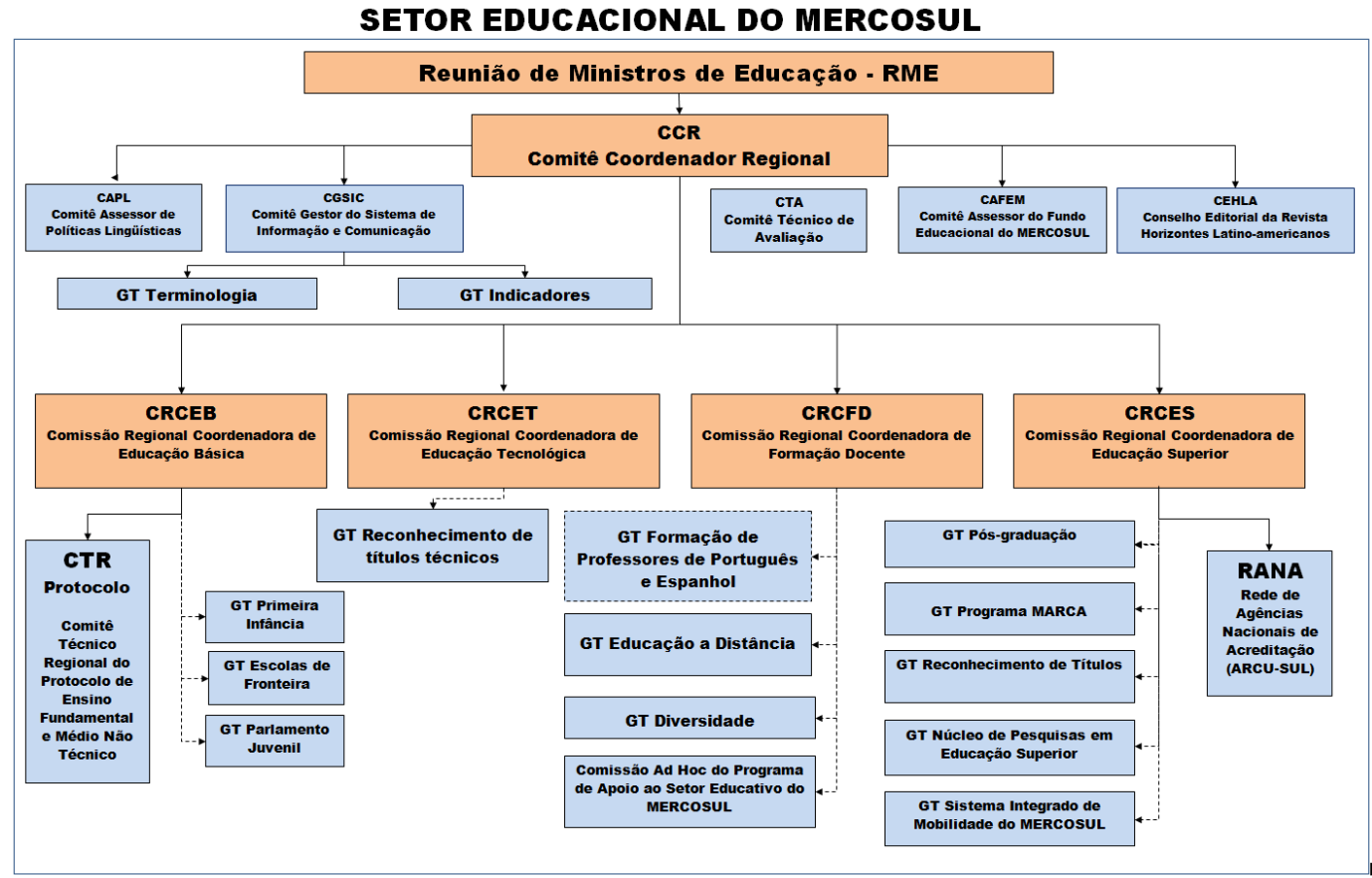

Figura 1 - Organograma do SEM

Fonte: Mercosul (s/d)

v.3

n.1 1 p.46-65


A atual configuração do Setor foi constituída com o Plano 2011-2015, mantendo a sistemática de considerar três funções principais, a política, a técnica e a executiva, e as atribuições dos principiais entes. A Reunião dos Ministros de Educação (RME) e o Comitê Coordenador Regional (CCR) exercem a função política; a técnica, ficou com as Comissões Regionais Coordenadoras de Área (CRCAs), isto é, Comissão Regional Coordenadora da Educação Básica (CRC-EB), Comissão Regional Coordenadora da Educação Superior (CRCES), Comissão Regional Coordenadora da Educação Tecnológica (CRC-ET) e Comissão Regional Coordenadora da Formação Docente (CRC-FD), e a executiva, com os Grupos de Trabalho (GTs), Grupos Gestores de Projeto (GPP), Comissões ad hoc, Comitê de Gestão e Comitê Gestor de Informação e Comunicação (CGSIC).

O Mexa foi desenvolvido sob a gestão da Rede de Agências Nacionais de Acreditação (Rana), subordinada hierarquicamente à CRC-ES, ao CRC e à RME.

\section{A ELABORAÇÃO dO DESENHO DO MEXA}

Desde a formação do Grupo de Trabalho de Especialistas em Acreditação e Avaliação da Educação Superior (GTEAE) ${ }^{3}$, constituído ad hoc pelos Ministros de Educação em 1997 , o delineamento do desenho do mecanismo regional se deu coletivamente. Tal orientação pode ser observada pela própria função do Grupo, que consistia em homogeneizar os trabalhos das Comissões Consultivas de expertos, incumbidas de desenvolver as dimensões, os componentes, os critérios e os indicadores do processo. As Comissões eram constituídas por três membros de cada Estado participante, os quatro fundadores do bloco acrescidos de Bolívia e Chile na condição de Estados Associados, perfazendo um total de dezoito membros (HERMO, 2011), conferindo, assim, maior legitimidade à iniciativa.

Os esforços do GTEAE resultaram no Memorando de Entendimento sobre a Implementação de um Mecanismo Experimental de Acreditação de Cursos para o Reconhecimento de Títulos de Graduação Universitária nos Países do Mercosul, Bolívia e Chile (Mexa), firmado em 1998 pela RME e pelos Estados Associados Bolívia e Chile, que consubstanciou os contornos do Mexa. Este documento constitui a primeira proposição de regulação da matéria, precisando termos técnicos a fim de uniformizar o entendimento de temas específicos, em face das diferenças entre os sistemas educacionais e avaliativos nacionais e o surgimento de novos atores institucionais ligados ao Setor Educacional do Mercosul.

\footnotetext{
${ }^{3}$ A sigla corresponde a Grupo de Trabajo de Especialistas em Acreditación y Evaluación de la Educación Superior em espanhol. Hermo (2011) utiliza a denominação Grupo de Trabajo de Especialistas em Evaluación y Acreditación Universitária, enquanto Guilayn (2012), Grupo de Trabalho de Especialistas em Avaliação e Credenciamento.

v. 3
}

n. 1


A definição do termo "acreditação"4 foi trazida como primeiro princípio do Mexa, nos seguintes termos:

processo mediante o qual se outorga validade pública, de acordo com as normas legais nacionais, aos títulos universitários, garantindo que os cursos correspondentes cumpram com requisitos de qualidade previamente estabelecidos no âmbito regional. Este processo estará baseado em mecanismos de avaliação que permitam garantir a devida formação dos titulados (MERCOSUL, 1998).

Assim, o Mexa diferenciava-se dos processos de acreditação em geral pela especificidade de suas normas terem sido acordadas a partir de um bloco econômico regional. $\mathrm{O}$ respeito às legislações de cada país e à autonomia das instituições universitárias reforça o caráter intergovernamental do Mercosul e se reflete na adesão voluntária das universidades. Poderiam participar do Mexa somente instituições reconhecidas em âmbito interno, habilitadas para outorgar título de graduação, cujos cursos contassem com egressos.

A RME ficou responsável por definir questões de ordem pragmática como a escolha das áreas e cursos que seriam submetidos ao processo, desde que a exigência de título universitário ou equivalente legal fosse obrigatória para o exercício profissional, e dos critérios e parâmetros de qualidade comuns para cada curso e o período de validade da acreditação concedida.

Dos Estados do bloco, as participações da Argentina e do Brasil, que apresentavam maior experiência em avaliação de cursos superiores, foram decisivas para determinar os procedimentos avaliativos do projeto de acreditação. Para o processo, foram previstas duas etapas, uma de autoavaliação e outra de avaliação externa; a primeira seria realizada institucionalmente pelo próprio curso, cujo relatório instruiria a segunda, a visita in loco do Comitê de Pares, que deveria emitir parecer. A indicação inicial para a composição do Comitê era de, ao menos, um especialista de cada um dos países do Mercosul.

A gestão e implementação dos procedimentos nacionalmente ficou a cargo de um novo ator, a Agência Nacional de Acreditação (ANA), que deveria ser indicada por cada Estado à RME. Para figurar como ANA, o ente deveria apresentar quatro características: 1) ser pessoa jurídica de direito público, reconhecida em conformidade com as disposições legais vigentes em seu país de origem; 2) ter caráter coletivo em sua conformação; 3) ser composta por membros idôneos e 4) ter a autonomia de suas decisões respeitadas. Mantendo o paralelismo da natureza coletiva do processo, as ANAs integraram a Rede de Agências Nacionais de Acreditação (Rana), órgão que foi incorporado ao SEM e responsável pelas decisões sobre o processo de acreditação e seu ditame final.

\footnotetext{
${ }^{4}$ Note-se que até 2011, o termo acreditación era traduzido como "credenciamento" nas versões em português dos documentos oficiais do Mercosul, o que causava transtornos para a compreensão da natureza da acreditação como certificação de qualidade, tendo em vista que credenciamento corresponde a ato autorizativo para início de atividades de Instituição de Educação Superior.

\begin{tabular}{l|l|l|l|l|l|l} 
(C) Rev. Inter. Educ. Sup. & Campinas, SP & v.3 & n.1 & p.46-65 & jan./abr. 2017 & ISSN 2446-9424 \\
\hline
\end{tabular}
}


O processo de acreditação deveria seguir o seguinte rito, sucintamente: a) a partir de convocatória, a instituição responsável pelo curso procederia à inscrição no Mexa, devendo esta ser analisada pela respectiva ANA; b) aceita a inscrição, com base no relatório de autoavaliação, o Comitê de Pares prepararia sua visita; c) o resultado do processo de acreditação seria emitido por resolução expedida pelas ANAs após homologação pela Rana, devendo a decisão ser comunicada à RME.

A outorga da acreditação não deveria exceder o prazo de cinco anos e deveria implicar o reconhecimento de títulos de graduação intrabloco, não conferindo o direito ao exercício laboral, tendo em vista que a atividade profissional é regulada por Conselhos de Classe e não está diretamente vinculada aos meios educacionais e acadêmicos (MERCOSUL, 1998).

Na revisão do Mecanismo em 1999, o Comitê de Pares sofre algumas alterações. Provavelmente considerando questões práticas, já que em nenhum momento no Memorando é feita referência à capacitação dos pares avaliadores e ao financiamento do Mexa, o Comitê é reduzido a três membros, devendo um deles ser do país do curso em avaliação e dois de outros Estados.

Como desdobramento do Segundo Plano do SEM, em dezembro de 1998 a RME definiu as áreas de agronomia, engenharia e medicina para passar pelo Mexa. Estimava-se que até o ano 2000 as ANAS dos Estados participantes já estivessem preparadas para receber as primeiras solicitações de acreditação (ANDRÉS, 2010). Relata Hermo (2011) que, entre 1998 e 2000, foram estabelecidos os parâmetros para a aplicação do Mexa a partir das reuniões das Comissões Consultivas e do Grupo de Trabalho, realizando-se um pré-teste para verificação da adequação dos critérios e indicadores escolhidos. Neste pré-teste, cada Estado indicou duas instituições para cada um dos três cursos. As instituições selecionadas preencheram um formulário de autoavaliação, e as visitas de pares ocorreram entre setembro e outubro de 2000. O quadro abaixo traz a relação das instituições participantes:

Quadro 1. Instituições de Ensino Superior por curso que participaram do pré-teste para o Mexa

\begin{tabular}{|l|l|l|}
\hline \multicolumn{1}{|c|}{ Curso } & \multicolumn{1}{|c|}{ País } & \multicolumn{1}{c|}{ Universidade } \\
\hline \multirow{5}{*}{ Agronomia } & Argentina & Universidad Nacional de Mar del Plata \\
\cline { 2 - 3 } & Brasil & Universidade Federal de Lavras \\
\cline { 2 - 3 } & Chile & Universidad Austral de Chile \\
\cline { 2 - 3 } & Paraguai & Universidad Nacional de Asunción \\
\cline { 2 - 3 } & Uruguai & Universidad de la República \\
\hline \multirow{5}{*}{ Engenharia } & Argentina & Universidad Católica de Córdoba \\
\cline { 2 - 3 } & Brasil & Universidade Estadual de Campinas \\
\cline { 2 - 3 } & Chile & Universidad Católica de Valparaíso \\
\cline { 2 - 3 } & Paraguai & Universidad Católica de Asunción \\
\hline \multirow{5}{*}{ Medicina } & Argentina & Universidad del Salvador \\
\cline { 2 - 3 } & Bolívia & Unversidad Mayor de San Simón \\
\cline { 2 - 3 } & Brasil & Universidade Federal de São Paulo \\
\cline { 2 - 3 } & Chile & Universidad de Valparaíso \\
\cline { 2 - 3 } & Paraguai & Universidad Nacional de Asunción \\
\hline
\end{tabular}

Fonte: Autor (2013). 
Em novembro, os resultados da experiência foram revisados e com base neles foram definidas as quatro dimensões do mecanismo: contexto institucional, projeto acadêmico, corpo docente, discente e egressos, além da infraestrutura.

Na XXII RME, realizada em 2002, foram concluídos e aprovados os trabalhos do GTEAE, que formulou os últimos ajustes do Memorando, e das Comissões Consultivas de Expertos dos cursos que passariam pelo Mexa, as quais elaboraram os critérios e parâmetros de qualidade comuns para cada curso. Este novo Memorando atualizou e substituiu o anterior adotando título idêntico e apresentou mais especificidades para a execução do Mexa nas "Normas Gerais de Operação e Procedimentos do Mecanismo Experimental de Acreditação do Mercosul, Bolívia e Chile". Na versão final, nota-se a preocupação com a delimitação da acreditação à área acadêmica pelo acréscimo de expressão explicativa à definição do termo técnico, assim reformulado:

\begin{abstract}
A acreditação é o processo mediante o qual se outorga validez pública, entendido exclusivamente como referido à qualidade acadêmica e de acordo com as normas legais nacionais, aos títulos universitários, garantindo que os cursos correspondentes cumpram com requisitos de qualidade previamente estabelecidos em nível regional. Dito processo estará baseado em mecanismos de avaliação que permitam garantir a devida formação os titulados (tradução livre) (grifo nosso) (MERCOSUR, 2002).
\end{abstract}

As maiores inovações do Memorando diziam respeito às especificações das Normas, que traziam seções dedicadas à apresentação de solicitação de acreditação, à estrutura geral do informe de autoavaliação, ao registro de avaliadores, à constituição dos Comitês de Pares e sua operacionalidade, aos possíveis ditames e ao resultado final do processo. As ANAs reafirmam-se como núcleo duro do Mexa, sendo-lhes conferida maior autonomia, com discricionariedade para definir procedimentos internos, desde que em consonância com os procedimentos estabelecidos pelas normativas e convencionadas na Rana ${ }^{5}$.

As Normas traziam os principais aspectos do desenvolvimento do Mexa que deveriam ser observados pelas ANAs. Desse modo, na apresentação da solicitação de acreditação, as instituições de educação superior deveriam se identificar e ao curso que pretendiam submeter à acreditação, declarando, explicitamente, que cumpriam os requisitos básicos estabelecidos pela respectiva ANA e que aceitavam os critérios de avaliação a serem aplicados e as normas básicas de acreditação definidas pelos Estados participantes do Mexa. Disso, decorria que concordavam em apresentar o informe de autoavaliação, em receber a visita do Comitê de Pares e aceitavam o resultado do processo.

Recebido o pedido e verificado se a IES e o curso cumpriam os requisitos, as ANAs dariam prosseguimento ao Mexa sendo recomendado que os procedimentos fossem objeto de

\footnotetext{
${ }^{5}$ Segundo Hermo (2011), nesta oportunidade a Rana é criada como órgão de execução do Mexa, enquanto o site oficial do SEM indica o ano de 2006.

\begin{tabular}{l|l|l|l|l|l|l} 
(C) Rev. Inter. Educ. Sup. & Campinas, SP & v.3 & n.1 & p.46-65 & jan./abr. 2017 & ISSN 2446-9424
\end{tabular}
}


acordo formal entre as instituições e a ANA, explicitando-se os direitos e obrigações de cada parte. Às ANAs caberia praticar os procedimentos de avaliação com integridade e independência; respeitar a confidencialidade da informação de caráter reservado; desenvolver atividades de assistência técnica necessárias para facilitar a aplicação do procedimento de acreditação; cumprir com as normas básicas acordadas regionalmente e informar à Secretaria pro tempore os resultados do processo. Por fim, o acordo deveria incluir a forma de financiamento do processo de acreditação, primeira vez que se faz menção ao tema, essencial para se implementar qualquer política pública.

Coube a cada ANA elaborar um Manual de Autoavaliação a partir de princípios gerais para a elaboração do informe, em face das idiossincrasias das culturas acadêmicas e avaliativas nacionais, a fim de possibilitar futuramente a convergência dessas regras e a elaboração de um Guia de Autoavaliação Regional. Como princípios, foram previstos: a) o estabelecimento de comparação do desempenho do curso com os padrões que constituem o marco fundamental da avaliação: metas, objetivos, critérios e parâmetros estabelecidos para cada curso no bloco; b) a incorporação da adequada combinação de elementos descritivos e analíticos, incluindo evidências das afirmações prestadas; c) a indicação das fortalezas e das debilidades do curso, e, no caso das últimas, a explicação de suas causas e as medidas que seriam propostas pela instituição de ensino superior para superá-las (MERCOSUL, 2002).

Os informes deveriam apresentar a seguinte estrutura, com três capítulos: I - Marco de referência; II - Avaliação do cumprimento dos critérios; III - Anexos. Do primeiro capítulo, constavam três partes: a) a contextualização institucional em que se enquadrava o curso, justificado no Informe Institucional constante do Anexo; b) a descrição do Projeto Acadêmico da unidade que oferecia o curso, considerando a natureza da formação ofertada e os resultados esperados relativos ao perfil desejado do egresso; c) a descrição das condições do processo de ensino-aprendizagem do curso, o perfil dos estudantes, dos docentes e os recursos para o desenvolvimento da aprendizagem geral do aluno. Desse modo, a primeira parte do informe de autoavaliação traria desde dados básicos, como a identificação da instituição de suas sedes, sua história institucional, organização, descrição das atividades acadêmicas com lista de cursos oferecidos por áreas de conhecimento, processo de admissão de alunos, participação em outros processos de avaliações externas, desempenho da instituição em relação ao fluxo de alunos por curso, atividades de pós-graduação relacionadas, número de cursos de mestrado e doutorado, políticas institucionais de pesquisa e as linhas desenvolvidas nos últimos três anos, atividades e políticas extensionistas, perfil, qualificação, plano de carreira e jornada do corpo docente, análise das bibliotecas e laboratórios até as avaliações institucionais realizadas no último triênio. No capítulo dois, o foco era voltado para a avaliação do grau de cumprimento dos critérios estabelecidos, metas e propósitos do curso, manifestando-se a instituição sobre as fortalezas e debilidades de cada item. A última parte do informe oportunizava a documentação das informações nele contidas. 
O cadastro de Pares Avaliadores restou sob a responsabilidade da Rana, com o dever de revisá-lo periodicamente e colocá-lo à disposição das ANAs para sua própria utilização e para consulta das instituições. Para a formação desse cadastro, as Comissões Consultivas propuseram as áreas a serem consideradas para a inclusão dos expertos, sua especialidade ou campo de formação e pré-requisitos, como ser o avaliador procedente de um dos seis Estados signatários do acordo, ter no mínimo 10 anos de exercício profissional, sendo reconhecido como especialista em sua área, entre outros.

Na composição do cadastro, houve a preocupação em se considerar especialistas tanto da área de formação como em gestão acadêmica e outros provenientes do meio profissional. Adicionalmente, os avaliadores deveriam dominar os idiomas espanhol e português e estar dispostos a cumprir as normas dos Comitês de Pares e a participar de oficinas de treinamento.

Recebido o informe da instituição, as ANAs designariam os Comitês de Pares para proceder à visita in loco, indicando o Presidente, feitas as convocações dos pares estrangeiros pelas ANAs de origem. Estariam aptos à seleção os avaliadores aprovados nas oficinas de treinamento, em regra. Havia igualmente a preocupação com a lisura da avaliação externa, cuidando-se para que não houvesse conflitos de interesse entre os pares avaliadores e as instituições. Com esse intuito, previu-se um prazo definido pela ANA para que a instituição se manifestasse sobre a objeção da composição do Comitê.

A função do Comitê de Pares consistiria em validar (ou não) o informe de autoavaliação e a documentação apresentada, verificando o grau em que o curso se ajustava aos critérios e parâmetros estabelecidos, avaliando o nível de cumprimento das metas e objetivos definidos. Na visita, eram consideradas as entrevistas com a comunidade acadêmica. Ao final, o Comitê de Pares se reunia para listar as observações que pudessem ser expostas às autoridades do curso em informe oral. Cada membro deveria elaborar um informe e encaminhá-lo para o Presidente para a confecção do informe final do Comitê, que, se aprovado, deveria ser enviado para a ANA no máximo 30 dias após a visita.

No informe, cada um dos critérios deveria ser tratado, explicitando a opinião do grupo quanto ao cumprimento dos padrões estipulados, analisando as metas e os objetivos institucionais e a qualidade do processo de autoavaliação desenvolvido pela instituição; por fim, o Comitê deveria se pronunciar sobre a outorga ou denegação da acreditação.

$\mathrm{Na}$ emissão de seus ditames, as ANAs deveriam considerar as conclusões do informe de autoavaliação, o informe do Comitê de Pares, o resultado de outros processos de acreditação nacionais ou estrangeiros a que o curso se submeteu anteriormente e outros antecedentes legais ou regulamentos nacionais. Findo o processo de avaliação, a acreditação seria concedida por meio de Resolução da ANA somente ao curso que cumprisse satisfatoriamente os requisitos do Mexa; no caso de se cumprir satisfatoriamente a maioria dos itens essenciais e mediante a apresentação de um plano razoável para superar as

\begin{tabular}{l|l|l|l|l|l|l} 
(C) Rev. Inter. Educ. Sup. & Campinas, SP & v.3 & n.1 & p.46-65 & jan./abr. 2017 & ISSN 2446-9424
\end{tabular}


deficiências identificadas, a decisão poderia ser adiada por um ano. Uma vez negada a acreditação, nova solicitação poderia ser interposta após dois anos. Independentemente do resultado, todas as IES seriam notificadas oficialmente da decisão, assim como a Secretaria pro tempore e a Rana; contudo, apenas as acreditações concedidas seriam informadas à RME e disponibilizadas no Sistema de Informação do Mercosul (SIC), o que reforça a ideia do processo para a melhora da qualidade e não para a estigmatização.

\section{A APLICAÇÃO DO MEXA}

Dando prosseguimento aos trabalhos de aplicação do Mexa, a realização das Oficinas de Capacitação de Pares Avaliadores por curso obedecia à ordem de aplicação gradual e escalonada definida pela RME. O processo para inscrição voluntária foi aberto em outubro de 2002 para agronomia, no segundo semestre de 2003 para engenharia e no primeiro semestre de 2004 para medicina, ocorrendo as visitas de pares entre outubro de 2003 e março de 2005, e entregues os primeiros resultados no final deste ano (HERMO, 2011).

A aplicação do Mexa se deu entre os anos de $2002^{6}$ e 2006 com convocatórias consecutivas para agronomia, engenharia (civil, química, industrial, eletrônica e mecânica) e medicina. Acordou-se que cada Estado indicaria no máximo cinco cursos para agronomia, três especialidades de engenharia e, no máximo, seis cursos, e até três cursos para medicina, sendo, ao final, acreditados 62 cursos, dos quais 12 eram brasileiros (MERCOSUL, 2008 b), conforme os quadros abaixo:

Quadro 2. Cursos acreditados por país no Mexa

\begin{tabular}{|c|c|c|c|c|c|c|c|}
\hline País & Argentina & Bolívia & Brasil & Chile & Paraguai & Uruguai & Total \\
\hline $\begin{array}{l}\text { Curso } \\
A \text { monionis }\end{array}$ & 5 & 4 & 3 & 5 & 1 & 1 & 10 \\
\hline Agronomia & 5 & 4 & 3 & 5 & 1 & 1 & 19 \\
\hline Engenharia & 6 & 6 & 6 & 0 & 6 & 5 & 29 \\
\hline Medicina & 3 & 3 & 3 & 3 & 1 & 1 & 14 \\
\hline Subtotal & 14 & 13 & 12 & 8 & 8 & 7 & 62 \\
\hline
\end{tabular}

Fonte: Autor (2010).

Concisamente, foram examinados dois aspectos no Mexa: se o curso cumpria os requisitos relativos a seu entorno institucional, suas características próprias, recursos humanos e infraestrutura; e a capacidade de o curso de se autoavaliar, reconhecer suas debilidades e ações possíveis para sua melhora (URUGUAY, 2009).

Comparativamente aos processos de avaliação da educação superior nacionais, o Mexa pode ser considerado relativamente simples, composto por um relatório de autoavaliação, visita de pares e outorga da acreditação, como pondera Hermo (2011).

\footnotetext{
${ }^{6}$ No Manual do Sistema Arcu-Sul de 2008, consta que o Mexa foi aplicado entre os anos de 2004 e 2006 (MERCOSUL, 2008, p. 4), contudo, há relatos de atividades em 2002, como se observa ao longo do texto.
} 
Contudo, a aplicação do Mexa e seu formato ímpar descortinam questões subjacentes e situações institucionalmente inusitadas que repercutem na consolidação do processo de acreditação regional.

\section{OS IMPACTOS DO MEXA}

Apesar do caráter experimental, o Mexa representa uma inovação em matéria educacional, figurando como um esforço realizado por Estados com sistemas educacionais diferentes para estandardizar a qualidade de seus cursos de graduação a fim de possibilitar o estabelecimento um sistema de acreditação regional. Sua operacionalização requereu a criação de órgãos específicos, como as ANAs e a Rana, mesmo dos Estados que não possuíssem sistema de avaliação da educação superior.

Note-se que, das três instâncias de governo e gestão consideradas por Fulquet (2006) envolvidas no processo, a RME, as ANAs, e a Rana, as duas últimas apresentam singularidades intrínsecas ao processo de acreditação formulado para um bloco regional de natureza intergovernamental.

Apesar das incertezas sobre o momento de constituição da Rana, é no Mexa que se conforma sua atuação como ente coordenador de atividades de acreditação da Educação Superior e sua natureza colegiada sui generis, formada pelas ANAs que, por sua vez, não obstante terem sido criadas pelas legislações nacionais, são indicadas pelos Estados-membros e Associados para desempenharem funções de cunho transnacional. Esse quadro pode trazer outras consequências que se convertem em entraves para a aplicação dos procedimentos de acreditação, levando os Estados a promover adaptações e a repensar seus sistemas avaliativos. Tendo em vista esse aspecto, a Convocatória para participar do Mexa abriu a possibilidade para os Estados que não tivessem constituída sua ANA de participar por meio de Comissões ad hoc, fazendo menção expressa à necessidade de uma das ANAs emitir as acreditações para a Bolívia ${ }^{7}$.

Das ANAs dos Estados-membro originários do bloco, apenas a argentina, a Comisión Nacional de Evaluación y Acreditación Universitária (Coneau), criada em 1995 pela Lei n. 24.521 de 20 de julho, ajustava-se ao perfil e aos requisitos exigidos pelo Mexa, executando, via acordo, os procedimentos acreditatórios também para a Bolívia. Conforme um dos entrevistados argentinos, a Coneau limitou-se a confeccionar os projetos de resolução dos cursos acreditados, sendo os procedimentos de avaliação executados e financiados pela Bolívia. O Brasil, que não possui órgão de acreditação nacional por não comportar esse

\footnotetext{
${ }^{7} \mathrm{Um}$ dos entrevistados argentinos informou que a lei que criava o sistema de avaliação nacional havia sido considerada inconstitucional pelo Tribunal Constitucional Boliviano em função de objeção do Conselho de Reitores. Observa este entrevistado que apesar das controvérsias sobre a instalação de um sistema de avaliação nacional, não foi feito óbice à participação boliviana no processo de acreditação regional.
}

v.3

\begin{tabular}{|l|l|l|} 
n.1 & p.46-65 & jan./abr. 2017 \\
\hline
\end{tabular}

ISSN 2446-9424 
instituto em seu sistema avaliativo, ao invés de instituir uma Comissão ad hoc indicou dois órgãos para participar da Rana, o Conselho Nacional de Educação (CNE), órgão colegiado cujas atribuições são de ordem normativa, deliberativa e de assessoramento ao Ministro da Educação em matéria de competência federal, e a Secretaria de Educação Superior (SESu), unidade do Ministério da Educação que era responsável, à época, pelos processos de avaliação e de regulação de cursos de graduação e das instituições de ensino superior, como lembra um dos entrevistados brasileiros. Não obstante nenhum dos órgãos que compartilharam a função de ANA exercesse atividades de execução de processos de avaliação, restou à SESu fazê-lo para o Mexa. Isso possivelmente se deu porque a SESu vinha participando do GT Mercosul, antes mesmo da formação do GTEAE, apesar de não ter institucionalizada sua atuação internacional naquele momento, e por integrar a Comissão Técnica Regional de Educação Superior do Mercosul, que conduziu os trabalhos do processo de acreditação, entendendo-se desnecessária sua nomeação como ANA por pertinência, como informa um dos entrevistados brasileiros. Ainda, esse entrevistado agrega que após análise do Mexa, os membros do CNE indicaram que a SESu deveria coordená-lo.

Guilayn (2012) observa que o CNE foi listado como ANA, mas as ações foram conduzidas pela SESu, o que vai ao encontro das informações prestadas a esse respeito pelo entrevistado acima citado de que em nenhum instante o CNE participou do processo de acreditação do Mercosul efetivamente. Esse mesmo entrevistado acrescenta que a conformação do CNE e suas atribuições são distintas das definidas para o processo de acreditação do Mercosul e do perfil requerido para a designação da instância nacional que integra o sistema de acreditação, mesmo constando como ANA em documentos oficiais, como na Ata 02/04 da RME. Ao que tudo indica, o CNE foi apontado como ANA considerando-se sua experiência interna relativa ao reconhecimento de cursos e para atender também ao requisito de que esta fosse composta por órgão de natureza colegiada, relatando outro entrevistado brasileiro que as acreditações do Mexa foram coordenadas pela SESu, mas que todo o processo passou pela assessoria internacional do Secretário da Educação Superior.

Interessante notar a praxe descrita pelo primeiro entrevistado brasileiro no tocante ao processo de legitimação de órgãos para atuar no SEM, cujo registro em atas da indicação ou participação em reuniões passa a ser o documento que legitima sua atuação. Segundo este entrevistado, as atas são aprovadas por instâncias superiores, como a Rana, a RME e a Secretaria do SEM, e que este seria o processo de aprovação formal do bloco, reservado à celebração de memorandos, protocolos e afins. Dos procedimentos nacionais, entende que, em geral, a nomeação só é requerida em dois casos: quando há mais de uma instância com atribuições semelhantes ou quando não há no país uma instância responsável compatível. Contudo, tal situação gera outro fato inusitado no caso do Brasil, já que as funções que são atribuídas às ANAs no processo de acreditação ampliam por via de acordo internacional as competências que lhe foram delegadas pela legislação interna. No Mercosul, bloco intergovernamental, as decisões de âmbito regional devem passar pelos trâmites previstos no 
ordenamento jurídico interno de cada Estado-membro para, por fim, serem ratificadas ${ }^{8}$ e, então, comprometerem-se os Estados ao seu cumprimento. Assim, no processo de incorporação de tratados ao ordenamento jurídico brasileiro, uma vez aprovados pelas instâncias competentes, assumem o status de lei ordinária, como regra geral. Desta feita, o órgão que faz as vezes de ANA poderia ter sua competência modificada com a ratificação do acordo ou a simples aprovação de uma ata por uma instância superior do SEM, o que poderia, em tese, colocar em xeque o princípio do respeito às legislações nacionais. Ainda, tendo-se em vista que não foi localizado no site do Sistema Consular Integrado/Sistema de Atos Internacionais a ratificação do Tratado do Mexa pelo Brasil, os atos da SESu como ANA podem ser considerados legitimados pela via do costume internacional, por uma praxe que vem sendo adotada como legítima e gera relações jurídicas das quais emanam direitos e deveres.

Desta maneira, órgãos nacionalmente criados poderiam ter expandidas suas competências pela ratificação dos tratados, ou ainda poder-se-ia considerar que a ampliação da competência dos órgãos indicados como ANA se deu pela via do costume internacional em face da nomeação para exercer tal função por autoridades legitimadas para representar o Estado oficialmente, já que o processo de ratificação muitas vezes é finalizado após a execução dos atos objeto do acordo internacional. Lembra Amaral Júnior (2008, p. 185) que "a emergência do costume é extraordinariamente facilitada pela existência de resoluções e recomendações que indicam a tomada de posição da organização internacional sobre alguma matéria considerada importante", podendo-se assim justificar a validade dos atos praticados pelas ANAs. Entendimento diverso poderia comprometer as negociações do SEM e a credibilidade da participação do Brasil, embora persistam incongruências em relação ao direito administrativo interno.

Em outros Estados-membro do bloco em que a prática da acreditação e da avaliação de cursos de graduação era incipiente ou inexistente, a participação no Mexa surtiu maior impacto, como no caso do Paraguai e do Uruguai. Para Caillón e Robledo (2009), no Paraguai, de fato, a avaliação e acreditação do ensino superior se deu a partir de sua participação no Mexa e com o estabelecimento da Agencia Nacional de Evaluación y Acreditación de la Educación Superior (Aneaes) com a Lei n. 2.072, de 13 de fevereiro de 2003, não obstante contasse com um órgão responsável pela atividade universitária, o Conselho de Universidades, instituído em 1993, que não chegou a implantar o sistema de avaliação e acreditação de cursos universitários previsto na Lei de Universidades (PEÑA, 2004).

Inicialmente, para executar os procedimentos do Mexa, foi nomeada pelo Poder Executivo uma comissão ad hoc integrada por representantes do Ministério da Educação e

\footnotetext{
${ }^{8}$ Como lembra Amaral Júnior (2008), o procedimento de ratificação dos tratados não é regulado pelo direito internacional, mas pela ordem jurídica interna, possibilitando ao legislador nacional o reexame do acordo antes que o Estado se comprometa internacionalmente.
} 
Cultura, do Conselho Nacional de Educação e Cultura e do Conselho de Universidades, enquanto, paralelamente, autoridades do Ministério da Educação, do Congresso Nacional e especialistas elaboravam o projeto de lei que culminou com a criação da Aneaes.

O modelo incorporado pelo Paraguai assemelha-se ao argentino, procedendo-se à avaliação de instituições e acreditação de cursos de graduação e pós-graduação, como observa Lagoria (2010), apresentando vários pontos em comum, como a acreditação obrigatória para determinados cursos, como direito, medicina, odontologia, engenharia, arquitetura e engenharia agronômica, além de outros que habilitem para o exercício de profissões cuja prática possa causar dano à integridade de pessoas ou a seu patrimônio, conforme o artigo $2^{\circ}$ da Lei n. 2.072.

A consonância do sistema paraguaio com o sistema de acreditação regional traz como grande vantagem a convergência dos conceitos operacionais internos e externos, elaborados a partir da experiência de Estados em que o tema já estava em pauta há mais de duas décadas, como Brasil e Argentina, e consenso entre expertos, possibilitando uma atuação focada de sua ANA e clareza de seu papel nas duas searas. Assim, um dos objetivos da proximidade entre ambos os processos era justamente propiciar que os cursos a serem acreditados regionalmente já tivessem passado por processo semelhante internamente ou que fossem simultâneos (AUTORES, 2011).

Quanto ao Uruguai, para participar do Mexa, seguiu a recomendação da Convocatória e instituiu Comissões ad hoc por curso. Entre os motivos para o prolongamento dos debates sobre a criação de uma ANA, pode-se identificar a particularidade intrínseca do sistema educacional superior uruguaio, em que somente instituições privadas passam por um processo de autorização e reconhecimento de cursos de graduação e pós-graduação, não contando com um sistema geral de avaliação ou acreditação (LAGORIA, 2010).

Como pondera Lemez (2004), a vontade política manifestada pelos Ministros de Educação e os compromissos assumidos no âmbito do Mercosul muitas vezes ignoram as condições reais de consecução da implantação de um sistema regional de acreditação de cursos universitários e as discussões técnicas internas que vão desde a definição do próprio objeto do acordo até questões de competência da ANA. Some-se a tal fato que o processo no âmbito legislativo para a operacionalização dos acordos é complexo e que depende da vontade política para entrar na pauta do dia.

Gianciácomo (2009) nota que as dificuldades na articulação dos trabalhos relativos às atividades de acreditação refletem as divergências na estrutura interna, grau de desenvolvimento e tempos de criação das ANAs, o que afeta igualmente outros programas do SEM, como o Programa de Mobilidade, tendo em vista que somente os cursos acreditados podem dele participar. 


\section{A META-AVALIAÇÃo dO MEXA}

Em 2006, a Rana promoveu a meta-avaliação do Mexa e considerou-se adequada sua inserção como uma das atividades centrais do Plano do SEM, reconhecendo-se a acreditação da qualidade da formação de graduação como um elemento efetivo para melhorar a qualidade da Educação Superior e um avanço no processo de integração. Preconizou-se, ainda, que a "institucionalização de um sistema de acreditação regional da qualidade para a formação da graduação constituía uma política de Estado conveniente a ser adotada pelos países do Mercosul" (MERCOSUL, 1998, p. 4).

Na XXXI Reunião dos Ministros de Educação, realizada naquele mesmo ano, deu-se por concluído o Mexa e foi aprovado Plano de Trabalho para a elaboração de um sistema de acreditação permanente nos mesmos moldes. Para Fulquet (2006) o objetivo do Mexa acabou direcionado para a harmonização acadêmica e não orientado diretamente ao mercado de trabalho, pretendendo-se tornar possíveis intercâmbios entre as instituições que tivessem obtido a acreditação de seus cursos, agregando a configuração de um espaço educacional regional. Ressalta Hermo (2011) que o Mecanismo se funda como uma experiência educacional díspar, construída em conjunto por seis Estados por iniciativa própria, independentemente de exigências ou auxílios de entes internacionais.

Ademais da importância de se mapear panoramicamente a qualidade acadêmica da região e o intercâmbio de experiências acadêmicas entre os cursos avaliados, um dos entrevistados argentinos destaca a constituição de um banco de pares avaliadores como importante ganho do Mexa. Ainda, outro entrevistado argentino realça que, para os professores que atuam como pares avaliadores é uma rara oportunidade para comparar in loco a qualidade de seus cursos com a de outros países, o que poderia motivá-los para a melhora das condições de seu próprio curso. Para ele, no Mexa, houve uma cooperação entre os Estados que possuíam maior experiência em avaliação que ajudaram a construir o sistema de avaliação dos países com menor experiência, como se deu no caso de Bolívia, Paraguai e Uruguai que receberam ajuda de Argentina, Brasil e Chile. No que tange às universidades, observa ainda que o mecanismo proporcionou o que dele se esperava, nada mais do que o prestígio por ter a qualidade reconhecida regionalmente de um curso, tendo em vista que no meio acadêmico o prestígio é relacionado à qualidade, muito embora nem sempre haja essa correspondência, e a uma possível participação em programa de mobilidade entre os cursos acreditados, sem nenhum outro efeito ulterior, assentindo neste particular um terceiro entrevistado argentino. Dadas as pretensões iniciais que ensejaram o Mexa, considera-se, apesar de seus logros, como a difusão da cultura da acreditação na região e a constituição e/ou consolidação das ANAs, que seu desenho é restrito e seus resultados estão aquém dos pretendidos para ensejar a concepção de um mecanismo permanente, dado que não restou esclarecido quais seriam as vantagens auferidas pelas universidades em participar do processo, tendo em vista que possuem autonomia para firmar convênios diretamente. 


\section{O LEGADO DO MEXA}

Como desdobramento natural do Mexa, em 2008 foi elaborado um processo de acreditação regional de caráter permanente através do Memorando de Entendimento para a criação e implementação de um Sistema de Acreditação de Cursos Universitários para o Reconhecimento das Respectivas Titulações no Mercosul e Estados Associados, aprovado na XXXIII Reunião de Ministros de Educação de 2007. Este documento se converteu no Acordo sobre a Criação e Implementação de um Sistema de Acreditação de Cursos Universitários para o Reconhecimento da Qualidade Acadêmica das Respectivas Titulações do Mercosul e Estados Associados por meio da Decisão 17/08 do Conselho Mercado Comum? .

O Sistema traz em seu bojo questões de fundo a dirimir que colocam de sobreaviso sua continuidade, sob o risco de, na prática, não superar o caráter experimental do Mexa, como o reconhecimento de títulos. Some-se a esses fatores a adesão da Colômbia e da Venezuela ao Sistema, o que implica a recomposição da Rana e da dinâmica de negociações e ajustes internos das ANAs destes Estados como observa um dos entrevistados argentinos.

O SEM apresenta o Sistema Arcu-Sul como meio para se fomentar, em primeiro plano, a melhora da qualidade dos cursos de graduação da região, tendo em vista patamares que favoreçam o desenvolvimento econômico, social, político e cultural e, indiretamente, a circulação de pessoas e a cooperação internacional das comunidades acadêmico-profissionais, proporcionando programas de mobilidade e a facilitação dos trâmites para o reconhecimento de títulos e diplomas universitários intrabloco (MERCOSUL, 2008b). Rasetti (2009) vislumbra que o modelo firmado para o Mercosul configura a avaliação como política multissetorial de integração, observando que os mecanismos de equivalência de qualidade de cursos estão intrinsecamente ligados aos objetivos políticos do bloco, tais como a convalidação de títulos e a habilitação futura para o exercício profissional na região, principal valor agregado que se espera do Sistema.

Assim, a priori, o Sistema contribuiria para a melhora dos cursos de graduação na região, o que talvez não possa ser aplicado a todos os Estados que participam do Sistema em função das diferenças entre seus sistemas educacionais, e também em virtude dos critérios exigidos internamente por algumas ANAs para selecionar os cursos que participam do Sistema, que exigem, de forma geral, que já tenham passado pelos processos de acreditação ou avaliação nacionais.

Para a aplicação do primeiro ciclo do Sistema Arcu-Sul, foram incluídos os cursos de arquitetura, enfermagem, odontologia e veterinária, totalizando $200 \operatorname{cursos}_{\text {acreditados }}{ }^{10}$. Para

\footnotetext{
${ }^{9}$ Órgão superior do bloco.

${ }^{10}$ Dados coletados a partir do site Oficial do Sistema Arcu-Sur (2016).

\begin{tabular}{l|l|l|l|l|l|l} 
(C) Rev. Inter. Educ. Sup. & Campinas, SP & v.3 & n.1 & p.46-65 & jan./abr. 2017 & ISSN 2446-9424 \\
\hline
\end{tabular}
}


o segundo ciclo, que ainda está em curso, foram adicionados, economia, farmácia e geologia e o Sistema contará com a participação do Equador.

Apesar de o Sistema se ampliar a cada ciclo, a possibilidade de sua aplicação em larga escala ainda se mostra remota em virtude de diversos fatores, como as diferentes formas de financiamento adotadas por cada um dos Estados para a execução dos procedimentos internos, especialmente em vista dos altos custos da visita de pares, herdado da concepção do Mexa de que uma das características do processo regional deveria ser a participação de avaliadores de diferentes países e por alguns Estados, como o Brasil ${ }^{11}$ e o Uruguai, não terem consolidado suas ANAs. Uma das maiores expectativas quanto ao segundo ciclo diz respeito à adoção da proposta argentina de tornar possível a aplicação dos processos avaliativos nacional e regional simultaneamente, sob determinadas condições, o que deve evitar um duplo procedimento para os mesmos fins e torná-lo economicamente mais viável.

A livre circulação de trabalhadores egressos dos cursos acreditados no Mercosul diz respeito a um segundo momento que o processo de acreditação regional acabou por não abranger, embora estejam intrinsecamente ligados. Esta questão passou a ser discutida separadamente, a partir da criação do Grupo de Trabalho para o Reconhecimento de Título de Graduação do Mercosul pela Reunião da Comissão Regional Coordenadora da Educação Superior em 2010.

O Grupo apresentou como delineamento para o sistema de reconhecimento de títulos que: a) este tivesse suas bases no sistema de acreditação; b) que o processo deveria ser implementado a partir de acordos de revalidação de títulos de cursos acreditados pelo Sistema Arcu-Sul com as universidades públicas, sujeito à análise específica de cada titulação; c) que o ingresso das instituições públicas no Sistema Arcu-Sul implicasse no compromisso de revalidar tais títulos; d) que o processo de revalidação não deveria exigir requisitos adicionais (MERCOSUL, 2010). Ainda, quanto ao exercício profissional, a proposta do Grupo se conduz no sentido de vincular a revalidação dos títulos com a habilitação profissional.

A partir do know-how do Mexa e do Sistema Arcu-Sul, a proposta é que o sistema de reconhecimento de títulos seja, igualmente, construído coletivamente e se baseie na aplicação de uma experiência piloto prevista para ocorrer na vigência do atual Plano do SEM (20162020) (MERCOSUR, 2016).

\footnotetext{
${ }^{11}$ Para participar do Sistema ARcu-Sul, o Brasil nomeou três órgãos como ANA, a Comissão Nacional de Avaliação da Educação Superior (Conaes), o Instituto Nacional de Pesquisas Educacionais Anísio Teixeira (Inep) e a Secretaria de Regulação e Supervisão da Educação Superior (Seres).

\begin{tabular}{l|l|l|l|l|l|l} 
(C) Rev. Inter. Educ. Sup. & Campinas, SP & v.3 & n.1 & p.46-65 & jan./abr. 2017 & ISSN 2446-9424
\end{tabular}
} 


\section{CONSIDERAÇÕES FINAIS}

Num cenário em que a importância das esferas internacionais e regionais se torna crescente, resulta necessário recuperar a história de uma política de avaliação da educação superior pouco conhecida no país. Com efeito, no Brasil, a avaliação nacional da educação superior tem enorme destaque, mas a participação do país no processo de acreditação regional é raramente divulgada. Recentemente, começam a ser pesquisadas essas políticas e seus efeitos. Assim, recuperar a história do Mexa, seu processo de construção participativa, seus procedimentos e aplicação, consiste em um resgate significativo para se compreender o Sistema Arcu-Sur e seus embaraços.

Ressalta-se, ainda, o papel fundamental do Mexa na introdução de práticas de avaliação de cursos na educação superior paraguaia, que não trazia a questão em sua agenda política até então e a rediscussão do tema no Brasil e no Uruguai, aonde tramitam projetos para a criação de Agências Nacionais de Acreditação que atendem ao modelo do Sistema Arcu-Sul, consolidando a cultura da acreditação e avaliação de cursos de graduação na região.

Embora o Mexa, em si, não tenha resultado no reconhecimento de títulos e na autorização para o exercício profissional, o Sistema Arcu-Sul tem sido ampliado tanto no número de cursos como no de Estados participantes a cada ciclo, consolidando-se como política pública regional para a Educação Superior. Estima-se que o Sistema seja aplicado em grande escala, futuramente, embora necessite de ajustes, com a instituição do mecanismo regional de reconhecimento de títulos, que se encontra em processo de elaboração.

\section{REFERÊNCIAS}

AMARAL JÚNIOR, Alberto do. Manual do candidato: noções de direito e direito internacional. Brasília: Funag, 2008.

ANDRÉS, Aparecida. A educação superior no setor educacional do Mercosul. Brasília: Biblioteca Digital da Câmara dos Deputados, 2010. Disponível em: <http://bd.camara.gov.br/ bd/bitstream/handle/bdcamara/6044/educacao_superior_andres.pdf? sequence $=1>$. Acesso em: 4 jul. 2011.

ARGENTINA. Ley Nacional de Educación Superior n. 24.521 (LES), de 20 de julho de 1995.

CAILLÓN, Adriana; ROBLEDO, Rocío. Procesos regionales en educación superior. El mecanismo de acreditación de carreras universitarias en el Mercosur. Reconocimiento regional de los títulos y de la calidad de la formación. Educación Superior y Sociedad, Caracas, ano 14, n. 1, p. 73-98, 2009. (Experiencias de convergencia académica en los países del Mercosur). 
FULQUET, Gastón. El proyecto educativo para el Mercosur y los debates en torno a la internacionalización de la educación superior. Buenos Aires: Centro Argentino de Estudios Internacionales, 2006.

GIANGIÁCOMO, Graciela. La educación Superior en el Sector Educativo del Mercosur. Origen, propuestas y realizaciones. In: GIANGIÁCOMO, G. (Comp.). La educación superior en el Sector Educativo del Mercosur. Remedios de Escalada: Universidad Nacional de Lanús, 2009. p. 11-19.

GUILAYN, Paulo Mayall. Diagnóstico estratégico da rede de agências nacionais de acreditação gestora do Sistema de Acreditação de Cursos Universitários do Mercosul (Arcu-Sul). 2012. Dissertação (Mestrado em Administração Pública) - Universidade de Brasília, Brasília, 2012.

HERMO, Javier Pablo. La acreditación regional de carreras en el Mercosur: presente e futuro. Saarbrücken: Editorial Académica Española, 2011.

LAGORIA, Silvana Lorena. Acreditación de la Educación Superior en Mercosur: posibilidades de integración. 2010. Monografia de conclusão do Curso Latino-Americano de Especialização em Políticas Públicas e Avaliação do Ensino Superior, Universidade Federal do Paraná/Universidade Federal da Integração Latino-americana, Foz do Iguaçu, 2010.

LEMÉZ, Rodolfo. Los procesos de evaluación y acreditación universitaria en Uruguay. In: LA EVALUACIÓN y acreditación de la educación superior en América Latina y Caribe. Caracas: IESALC, 2004. p 247-261.

MERCOSUL. Reunião dos Ministros de Educação. Memorando de entendimento sobre a implementação de um mecanismo experimental de credenciamento de cursos para o reconhecimento de títulos de graduação universitária nos países do Mercosul, de 19 de jun. de 1998.

MERCOSUL. Reunião dos Ministros de Educação dos países do Mercosul, Bolívia e Chile XXII. Ata 02/02: Memorando de entendimento sobre a implementação de um mecanismo experimental de credenciamento de cursos para o reconhecimento de títulos de graduação universitária nos países do Mercosul. [2002?].

MERCOSUL. Reunião dos Ministros de Educação dos países do Mercosul, Bolívia e Chile XXIII. Ata 02/04. [2004?].

MERCOSUL. Setor Educacional. Organograma. Disponível em: < http://edu.mercosur.int/pt-BR/mercosul-educacional/instancias.html >. Acesso em: 02 nov.2016.

MERCOSUL. Sistema de Acreditação de Cursos Universitários Mercosul. Busca de cursos acreditados. Disponível em: <http:// http://arcusul.mec.gov.br/index.php/pt-br/>. Acesso em: 15 nov. 2016. 
MERCOSUR. Consejo Mercado Común. Decisión 17/08. 2008. Acuerdo sobre la creación y la implementación de un sistema de acreditación de carreras universitarias para el reconocimiento regional de la calidad académica de las respectivas titulaciones en el Mercosur y Estados Asociados.

MERCOSUR. Reunión de Ministros de Educación. Acta 01/2010. [2010?]. Disponível em: $<$ http://edu.mercosur.int/pt-BR/documentos-categoria/finish/1349-2010/864-mercosur-rmeccr-crces-gtr-acta-n-01-2010.html>. Acesso em: 02 nov. 2016.

MERCOSUR. Reunión de Ministros de Educación. Acta 01/2016. [2016?]. Disponível em: $<$ http://edu.mercosur.int/pt-BR/documentos-categoria/finish/1351-2016/866-mercosur-rmeccr-crces-gtr-acta-n-01-2016.html>. Acesso em: 02 nov. 2016.

MERCOSUR. Setor Educacional do Mercosul. Sistema de acreditación de carreras universitarias para el reconocimiento regional de la calidad académica de sus respectivas titulaciones en el Mercosur y Estados asociados. Manual del sistema 2008-2010. 2008 b.

PARAGUAY. Lei n. 2.072 de 13 de fevereiro de 2003.

PEÑA, Haydee Gimenez. de. El proceso de acreditación de carreras en Paraguay. In: LA EVALUACIÓN y acreditación de la Educación Superior en América Latina y Caribe. Caracas: Iesalc, 2004. p. 191-201.

RASETTI, Carlos Perez. Cuestiones teóricas y metodológicas de evaluación y acreditación. Disponível em: <http://ead.pti.org.br/unila/course/view.php?id=7>. Acesso em: 26 out. 2009.

URUGUAY. Ministério da Educação. Preguntas frecuentes sobre el Mexa. Disponível em: <http://educacion.mec.gub.uy/mexa.htm>. Acesso em: 15 nov. 2009. 